Article

\title{
Performance of Waterborne Polyurethanes in Inhibition of Gas Hydrate Formation and Corrosion: Influence of Hydrophobic Fragments
}

\author{
Roman S. Pavelyev ${ }^{1,2}$, Yulia F. Zaripova ${ }^{2}$, Vladimir V. Yarkovoi ${ }^{2}$, Svetlana S. Vinogradova ${ }^{3}$, \\ Sherzod Razhabov ${ }^{3}$, Khasan R. Khayarov ${ }^{4}$ (D), Sergei A. Nazarychev ${ }^{1}$, \\ Andrey S. Stoporev 1,2,5,6®, Rais I. Mendgaziev ${ }^{5}$, Anton P. Semenov ${ }^{5}$, Lenar R. Valiullin ${ }^{7}$, \\ Mikhail A. Varfolomeev ${ }^{1,2, *}$ and Malcolm A. Kelland ${ }^{8}$ \\ 1 Department of Petroleum Engineering, Kazan Federal University, Kremlevskaya Str. 18, \\ 420008 Kazan, Russia; rpavelyev@gmail.com (R.S.P.); nazarichev.sa@gmail.com (S.A.N.); \\ stopor89@bk.ru (A.S.S.) \\ 2 Department of Physical Chemistry, Kazan Federal University, Kremlevskaya Str. 18, 420008 Kazan, Russia; \\ yu-ya98@yandex.ru (Y.F.Z.); waldemaryarkovoi@gmail.com (V.V.Y.) \\ 3 Department of Electrochemical Engineering, Kazan National Research Technological University, \\ Karl Marx Str. 68, 420015 Kazan, Russia; vsvet2000@mail.ru (S.S.V.); sherzodrazhabov@mail.ru (S.R.) \\ 4 Department of Organic Chemistry, Kazan Federal University, Kremlevskaya Str. 18, 420008 Kazan, Russia; \\ khayarov.kh@gmail.com \\ 5 Department of Physical and Colloid Chemistry, Gubkin University, 65, Leninsky Prospekt, Building 1, \\ 119991 Moscow, Russia; meda810@mail.ru (R.I.M.); semyonovanton@mail.ru (A.P.S.) \\ 6 Nikolaev Institute of Inorganic Chemistry SB RAS, Ac. Lavrentiev Ave. 3, 630090 Novosibirsk, Russia \\ 7 Federal Center for Toxicological, Radiation and Biological Safety, Nauchnyi Gorodok 2, \\ 420075 Kazan, Russia; valiullin27@mail.ru \\ 8 Department of Chemistry, Bioscience and Environmental Engineering, Faculty of Science and Technology, \\ University of Stavanger, N-4036 Stavanger, Norway; malcolm.kelland@uis.no \\ * Correspondence: mikhail.varfolomeev@kpfu.ru; Tel.: +7-843-233-7977
}

Received: 25 October 2020; Accepted: 28 November 2020; Published: 1 December 2020 updates

\begin{abstract}
The design of new dual-function inhibitors simultaneously preventing hydrate formation and corrosion is a relevant issue for the oil and gas industry. The structure-property relationship for a promising class of hybrid inhibitors based on waterborne polyurethanes (WPU) was studied in this work. Variation of diethanolamines differing in the size and branching of $N$-substituents (methyl, $n$-butyl, and tert-butyl), as well as the amount of these groups, allowed the structure of polymer molecules to be preset during their synthesis. To assess the hydrate and corrosion inhibition efficiency of developed reagents pressurized rocking cells, electrochemistry and weight-loss techniques were used. A distinct effect of these variables altering the hydrophobicity of obtained compounds on their target properties was revealed. Polymers with increased content of diethanolamine fragments with $n$ or tert-butyl as N-substituent (WPU-6 and WPU-7, respectively) worked as dual-function inhibitors, showing nearly the same efficiency as commercial ones at low concentration $(0.25 \mathrm{wt} \%)$, with the branched one (tert-butyl; WPU-7) turning out to be more effective as a corrosion inhibitor. Commercial kinetic hydrate inhibitor Luvicap $55 \mathrm{~W}$ and corrosion inhibitor Armohib CI-28 were taken as reference samples. Preliminary study reveals that WPU-6 and WPU-7 polyurethanes as well as Luvicap $55 \mathrm{~W}$ are all poorly biodegradable compounds; $\mathrm{BOD}_{\mathrm{t}} / \mathrm{COD}_{\mathrm{cr}}$ (ratio of Biochemical oxygen demand and Chemical oxygen demand) value is 0.234 and 0.294 for WPU-6 and WPU-7, respectively, compared to 0.251 for commercial kinetic hydrate inhibitor Luvicap $55 \mathrm{~W}$. Since the obtained polyurethanes have a bifunctional effect and operate at low enough concentrations, their employment is expected to reduce both operating costs and environmental impact.
\end{abstract}


Keywords: methane-propane hydrate; kinetic hydrate inhibitor; corrosion inhibitor; flow assurance; dual function inhibitor; waterborne polyurethane

\section{Introduction}

Gas hydrates occur under suitable pressure and temperature conditions during the production and transportation of hydrocarbons in wellbores, pipelines, and other equipment. These ice-like compounds are formed when low-molecular gases are entrapped into the cavities of a crystal lattice, consisting of water molecules structured through hydrogen bonds [1]. Hydrate particles may agglomerate, which results in hydrate plug and pipeline blockage. This impedes the fluids flow, thereby reducing transportation efficiency, increasing operating costs, as well as contributing to an industrial accident in extreme cases [2,3]. In addition, acidic environment can cause severe corrosion of the pipeline or other contact steel elements used in the production, transportation, storage, and refining of hydrocarbons, which reduces their service life (pipelines, etc.). Moreover, this can also lead to some accidents $[4,5]$.

The simultaneous injection of various oilfield reagents into a multiphase flow of formation fluids often leads to a decrease in their target properties or the occurrence of side effects. One of the reasons for such behavior is the interaction of these reagents with each other and/or with other flow components [6-11]. The injection of large quantities of oilfield reagents requires a more powerful infrastructure (additional storage tanks, injection pumps, and distribution pipelines) and a complex process of the additives regeneration [12]. It is worth it to note that a decrease in the variety of reagents used in the field, as well as the transition to biodegradable and low-toxic compounds, can have a beneficial effect on the environment and human health. This aspect is extremely relevant today. Thus, the development of efficient and biodegradable multifunctional reagents, which are safe for humans and the environment, seems to be an urgent trend in the oilfield chemistry today. Obtaining compounds with complex action provides the opportunity to reduce economic costs associated with flow assurance issues significantly. Ionic liquids, amino acids, and biopolymers (including modified ones) are considered in the literature as dual-function inhibitors (gas hydrate and corrosion inhibitors; GHCI) [11,12]. Typical kinetic hydrate inhibitors (KHIs) have anti-corrosion activity as well [13-15].

Despite the ability of ionic liquids to inhibit the formation of gas hydrates, they are practically not used in industrial processes with rare exceptions. This is due to the high cost of their production [16]. Besides, many ionic liquids are simultaneously toxic [17] and low biodegradable materials [18,19]. In addition, all ionic liquids studied to date are poor KHIs [20]. Amino acids, such as glycine, alanine, valine, leucine, isoleucine, tyrosine, serine, arginine, and lysine have also been studied as inhibitors of methane and carbon dioxide hydrate formation [12,20,21]. However, they are not sufficiently effective, stable in solutions, and also promote the growth of microorganisms, since they are a nutrient substrate for them [22,23]. Among biopolymers, a rather narrow range of compounds has been identified as dual-function inhibitors, namely chitosan, pectin, and starch (native biopolymers). In general, native biopolymers have a rather low ability to inhibit the formation of gas hydrates and corrosion. Some have limited solubility in water as well [12]. A promising approach for the GHCI preparation is the copolymerization of vinyl caprolactam and acrylic acid modified with groups which are known to possess anti-corrosive properties (imidazoles, quaternary ammonium groups) [24].

Earlier, our group obtained promising KHIs based on water-soluble polyurethanes [25], vegetable oils [26,27], as well as natural polymers such as chitosan [28]. These compounds possess a due action, additionally inhibiting corrosion $[27,28]$. Due to the presence of natural fragments and a large number of ester bonds, they were able to decompose relatively quickly under the influence of environmental factors. It should be noted that the class of polyurethanes as a whole is characterized by relatively good biodegradation indexes, which makes them promising for the development of various oilfield 
reagents $[29,30]$. It is known that the length of side chains in the polymer, along with their branching, has a significant effect on the hydrate formation inhibiting properties of polymers [31,32]. An increase in the length of the alkyl substituent in hexaalkylguanidinium salts was also shown to strongly affect the KHI properties of their mixtures with commercial kinetic hydrate inhibitor PVCap [33]. Thus, the current work is devoted to a systematic study of the dependence between the waterborne polyurethanes inhibiting properties (GHCI) and their structure, namely, the effect of the hydrophobicity (length and branching) of some fragments in the polymer molecule.

\section{Results and Discussion}

To assess the performance of WPUs as kinetic hydrate inhibitors, the rocking cells were employed. The variation of open circuit potential, Tafel slopes, and weight-loss measurements were used to determine the anti-corrosion activity of WPU. Biodegradability of WPU-6 and WPU-7 was assessed as well.

\subsection{Chemistry}

It is known that the development of new classes of KHIs focuses on polymers containing in their structure a combination of hydrophilic (primarily amide) and hydrophobic sites [20,34,35].

Thus, the structures of the polyurethanes synthesized in our group earlier fall within the basic requirements for the KHI structure. As one can see from Scheme 1, the urethane fragment of the synthesized polymers consists of an ester and amide parts, while the isophorone framework serves as a hydrophobic site in this case. The presence of salt fragments and PEG residue contributes to an increase in the solubility of polyurethanes in an aqueous medium and facilitates an additional interaction with water molecules through hydrogen bonds disturbing the local water structuring. This is one of the key factors in kinetic gas hydrates inhibition [36,37]. In addition, two more advantages of the developed inhibitors should be noted. (1) A positively charged fragment of a protonated tertiary amine resembling quaternary ammonium salts $[38,39]$ may provide antiagglomerant properties to the synthesized compounds; and (2) the negatively charged fragment imparts the properties of barrier corrosion inhibitors to polymers due to the ability to adsorb on the metal surface $[5,14,27]$. In this work, we introduced additional hydrophobic groups into the structure of polymers by replacing monoethanolamine with $\mathrm{N}$-substituted diethanolamines during polymerization. The ratio of the substituted diethanolamine with the acidic moiety was also varied. The reference samples were the previously described waterborne polyurethane 1 (WPU-1, $3.8 \mathrm{kDa}$ ) with a monoethanolamine fragment (Scheme 1) and the commercial KHI P(VCap-VP). In WPU-2, WPU-3, and WPU-4 polymers, unlike WPU-1, $N$-methyl-, $N$-butyl, and $N$-tert-butyldiethanolamine fragments were used instead of a monoethanolamine fragment, respectively. The polymers WPU-5, WPU-6, and WPU-7 contain the same fragments of diethanolamines, but their content was increased by 2.5 times by the same decrease in the propionic acid fragment.

\subsection{Gas Hydrate Experiments}

As the temperature decreased from $18.5^{\circ} \mathrm{C}$ to $-0.5^{\circ} \mathrm{C}$, a straight pressure drop occurred due to thermal gas compression. The gas consumption start point (deviation of pressure from linear dependence) corresponds to the hydrate onset temperature $\left(T_{o}\right)$. Figure 1 illustrates determination of $T_{o}$ and $\Delta T_{o}$ (hydrate onset subcooling). As seen from Figure 1a, hydrate formation started at $780 \mathrm{~min}$, which resulted in the induction period of hydrate onset of about $660 \mathrm{~min}$. The cooling at $1{ }^{\circ} \mathrm{C} / \mathrm{h}$ ended after $1200 \mathrm{~min}$. Rapid heating of the system to $33^{\circ} \mathrm{C}$ with subsequent rocking at this temperature for $3 \mathrm{~h}$ led to the complete dissociation of the hydrate phase and the equilibration of a two-phase gas-aqueous solution system. Table 1 and Figures 2 and 3 summarize the data for the effect of designed WPU on the hydrate nucleation and growth (kinetics of gas uptake) compared to reference compound WPU-1, commercial inhibitor $\mathrm{P}(\mathrm{VCap}-\mathrm{VP})$ (positive control) and pure water (negative control). In the $\mathrm{P}(\mathrm{VCap}-\mathrm{VP})$ system, $11.2 \%$ of relative pressure decrease occurs at $0.25 \mathrm{wt} \%$ dosage due to the hydrate 
formation by the end of the cooling stage (at $-0.5{ }^{\circ} \mathrm{C}$ ), while it reduces to $5.1 \%$ and $6.3 \%$ in the cases of the most effective polymers WPU-6 and WPU-7, respectively (Table 1 and Figure 2).

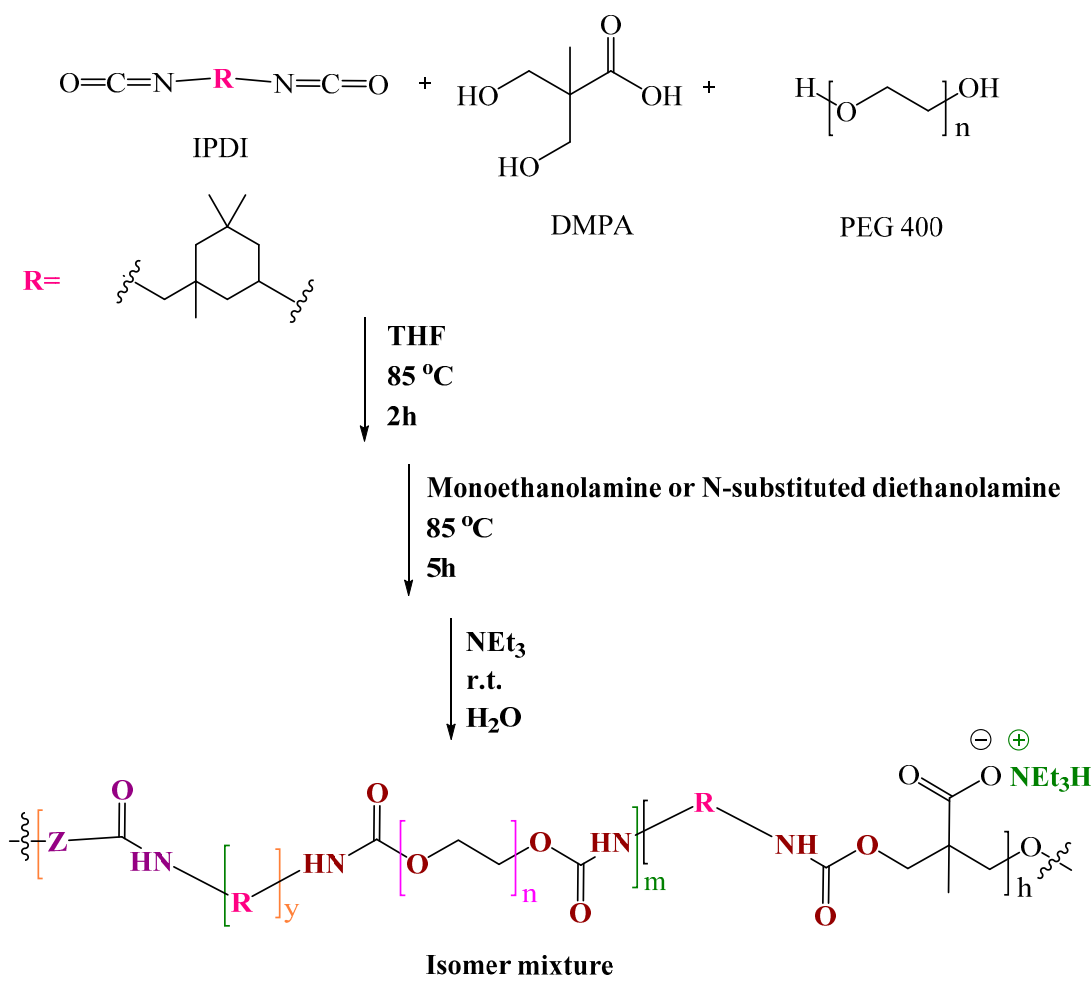

$\mathrm{Z}=$ Monoethanolamine or $\mathrm{N}$-substituted diethanolamine

WPU-1 - Z = monoethanolamine (1x);

WPU-2 - Z = N-methyldiethanolamine (1x);

WPU-3 - Z = N-butyldiethanolamine (1x);

WPU-4 - Z = N-tert-butyldiethanolamine (1x);

WPU-5 - Z =N-methyldiethanolamine $(2.5 \mathrm{x})$;

WPU-6 - Z = N-butyldiethanolamine (2.5x);

WPU-7 - Z $=$ N-tert-butyldiethanolamine (2.5x);

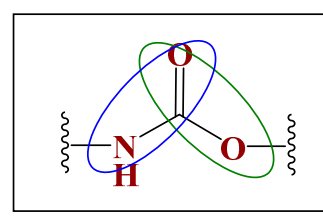

urethane fragment: amide part ester part

Scheme 1. Synthesis of waterborne polyurethanes (WPU).

(a)

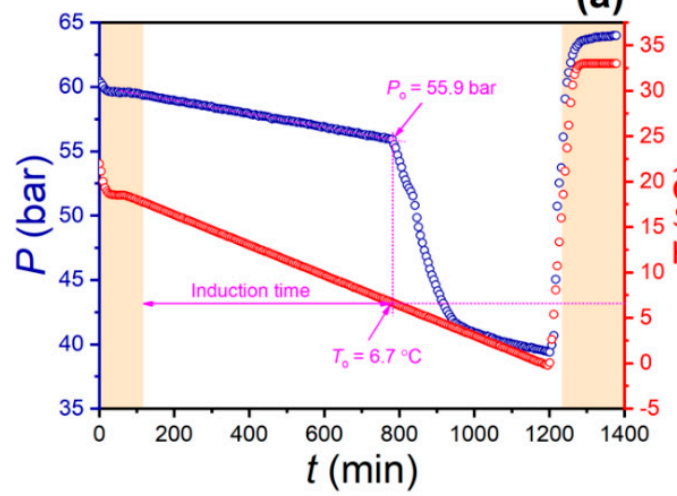

(b)

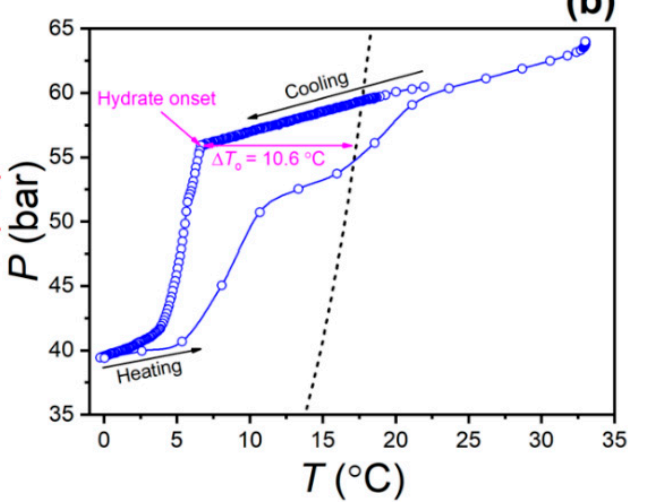

Figure 1. (a) Typical result of ramping experiment for a polyurethane solution ( $0.5 \mathrm{wt} \% \mathrm{WPU}-3)$; color-filled areas correspond to $P, T$-conditions outside the thermodynamic stability of gas hydrate, white area matches hydrate stability zone; (b) $P, T$-curve illustrating the determination of hydrate onset subcooling $\left(\Delta T_{o}\right)$; dashed line-experimental data for the equilibrium conditions of hydrate formation for the gas mixture [40]. 
Table 1. The results of ramping experiments by rocking cell technique.

\begin{tabular}{|c|c|c|c|c|c|c|c|}
\hline Sample & $\begin{array}{c}\text { Concentration } \\
(w t \%)\end{array}$ & $T_{o} *\left({ }^{\circ} \mathrm{C}\right)$ & $\begin{array}{c}\text { Standard } \\
\text { Deviation of } T_{o} \\
\left({ }^{\circ} \mathrm{C}\right)\end{array}$ & $\Delta T_{o}\left({ }^{\circ} \mathrm{C}\right)$ & $\begin{array}{c}\text { Standard } \\
\text { Deviation of } \Delta T_{o} \\
\left({ }^{\circ} \mathrm{C}\right)\end{array}$ & $\alpha * *(\%)$ & $\begin{array}{c}\text { Standard } \\
\text { Deviation of } \alpha \\
(\%)\end{array}$ \\
\hline Distilled water & - & 12.4 & 0.7 & 5.2 & 0.7 & 13.9 & 2.8 \\
\hline $\mathrm{P}(\mathrm{VCap}-\mathrm{VP})$ & 0.5 & 3.7 & 1.1 & 13.6 & 1.1 & 2.0 & 1.0 \\
\hline WPU-1 & 0.25 & \multicolumn{6}{|c|}{$\mathrm{n} / \mathrm{a}^{* * *}$} \\
\hline \multirow{2}{*}{ WPU-2 } & 0.25 & 8.6 & 0.4 & 8.9 & 0.4 & 16.1 & 10.2 \\
\hline & 0.5 & 7.6 & 0.1 & 9.8 & 0.1 & 26.8 & 1.8 \\
\hline \multirow{2}{*}{ WPU-3 } & 0.25 & 7.4 & 0.4 & 10.0 & 0.4 & 15.2 & 11.8 \\
\hline & 0.5 & 6.7 & 0.4 & 10.6 & 0.3 & 21.1 & 7.9 \\
\hline WPU-4 & 0.25 & 6.3 & 0.4 & 11.0 & 0.4 & 6.7 & 3.1 \\
\hline \multirow{2}{*}{ WPU-6 } & 0.25 & 5.7 & 0.5 & 11.6 & 0.5 & 5.1 & 2.4 \\
\hline & 0.5 & 6.2 & 0.4 & 11.2 & 0.4 & 6.6 & 4.6 \\
\hline \multirow{2}{*}{ WPU-7 } & 0.25 & 5.7 & 0.2 & 11.6 & 0.2 & 6.3 & 1.8 \\
\hline & 0.5 & \multicolumn{6}{|c|}{$\mathrm{n} / \mathrm{a}^{* * *}$} \\
\hline
\end{tabular}

${ }^{*} T_{0}$ is a hydrate onset temperature; ${ }^{* *} \alpha$ is relative pressure decrease; ${ }^{* * *} \mathrm{n} / \mathrm{a}$ means not available.
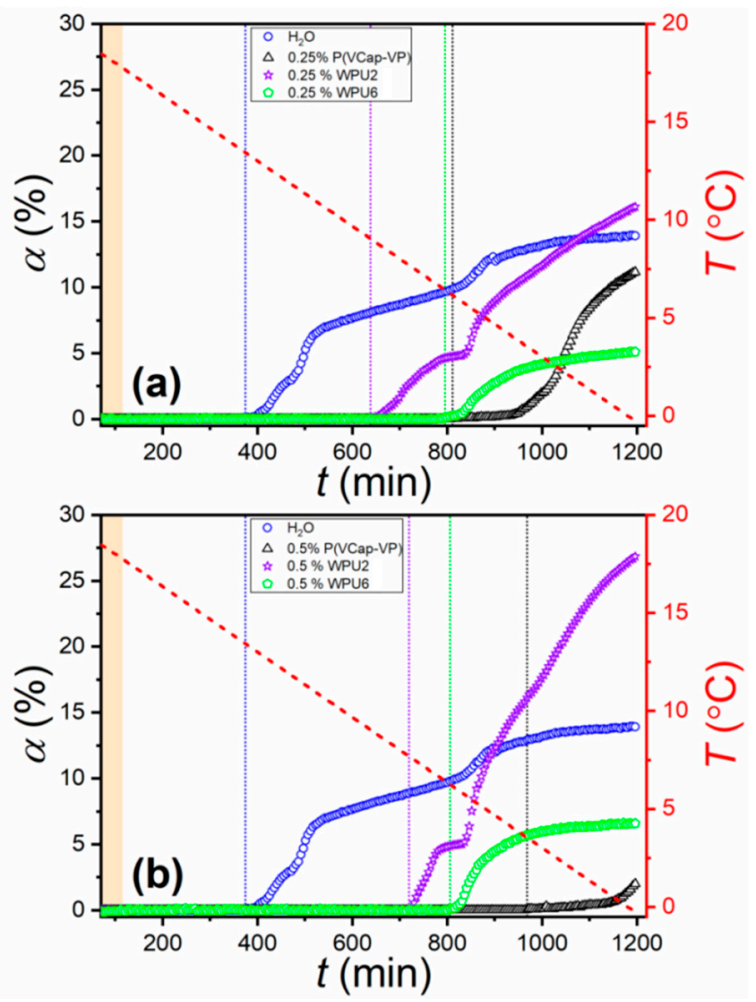

Figure 2. The gas consumption in the absence and presence of polyurethanes and $\mathrm{P}(\mathrm{VCap}-\mathrm{VP})$ at concentrations of $0.25 \mathrm{wt} \%$ (a) and $0.5 \mathrm{wt} \%(\mathbf{b})$; color-filled areas correspond to $P, T$-conditions outside the thermodynamic stability of gas hydrate, white area matches hydrate stability zone; red dashed lines are temperature plots; markers are mean values of relative pressure decrease for each sample; vertical color dashed lines show moment when a mean value for each sample becomes more than $0.07 \%$. 

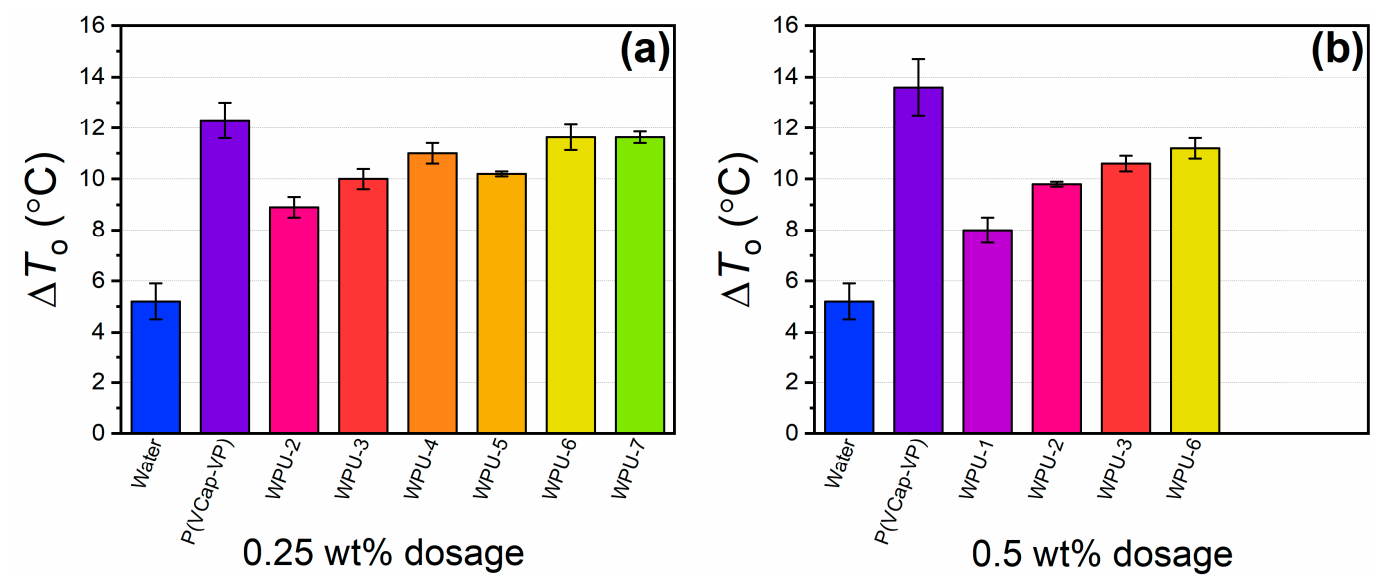

Figure 3. Mean hydrate onset subcooling $\Delta T_{o}$ for samples of synthesized polyurethanes at concentrations of $0.25 \mathrm{wt} \%$ (a) and $0.5 \mathrm{wt} \%$ (b). Error bars are standard deviations of $\Delta T_{0}$.

It should be noted that the replacement of monoethanolamine by $N$-substituted diethanolamines resulted in an increase in the inhibition power. For example, for WPU-1, the value of $T_{o}$ was $9.5 \pm 0.5^{\circ} \mathrm{C}$ even at a concentration of $0.5 \mathrm{wt} \%$. This was a higher $T_{0}$ value than for all WPU-2-WPU-7 inhibitors, which ranged from $8.6 \pm 0.4{ }^{\circ} \mathrm{C}$ to $5.7 \pm 0.5^{\circ} \mathrm{C}$ at $0.25 \mathrm{wt} \%$ dosage. For pure water and commercial $\mathrm{P}\left(\right.$ VCap-VP) at $0.25 \mathrm{wt} \%$, the onset temperature was found to be $12.4 \pm 0.7^{\circ} \mathrm{C}$ and $5.0 \pm 0.7^{\circ} \mathrm{C}$, respectively. As expected, an increase in the size of a substituent from methyl to $n$ - or tert-butyl facilitated a significant increase in the KHI activity of WPU. Thus, an increase in the content of these butyl groups in the polymer by 2.5 times due to the same decrease in the propionic acid fragment made it possible to obtain polyurethanes with performance comparable to that for $\mathrm{P}(\mathrm{VCap}-\mathrm{VP})$. For example, for polyurethanes with an $n$-butyl fragment, the statistically significant decrease of $T_{o}$ value from $7.4 \pm 0.4{ }^{\circ} \mathrm{C}$ for WPU-3 to $5.7 \pm 0.5^{\circ} \mathrm{C}$ for WPU- 6 occurs. The reason for this enhancement in the inhibition efficacy may lie both in the additional interaction of alkyl hydrophobic groups with open hydrate cavities on the crystal surface (crystal growth inhibition), and in perturbing the local water structure by the WPU involvement in hydrogen bonding (nucleation inhibition) [20,37,41-43]. However, unlike the commercial reagent $\mathrm{P}(\mathrm{VCap}-\mathrm{VP})$, an increase in the concentration of polyurethanes from $0.25 \mathrm{wt} \%$ to $0.5 \mathrm{wt} \%$ did not give much improvement to their inhibiting power. Nevertheless, the current study confirms that proper modification of such polyurethane polymers gives them KHI properties.

As seen from the dependencies in Figure 2, gas uptake due to hydrate formation in deionized water begins at $370 \mathrm{~min}$ of the experiment. Moreover, immediately after the appearance of the hydrate, its growth occurs at a relatively high rate. A similar regularity is also observed in the case of all polyurethanes. It can be seen that the gas hydrate growth at $0.5 \mathrm{wt} \%$ concentration of WPU occurs at a higher rate compared to $0.25 \mathrm{wt} \%$, especially at the initial stage. In the case of $N$-vinyl lactam-based KHI, hydrate growth proceeds for a rather long time at a relatively low rate after the hydrate onset, gradually accelerating. The difference in behavior between WPU and P(VCap-VP) with increasing concentration can be explained by the foaming properties of the polyurethanes [27]. Indeed, the formation of more stable foam at a higher concentration results in increased water-gas interface, which readily affects nucleation and growth rates of gas hydrates.

From the data in Figure 3, it follows that there is a general pattern at both studied concentrations $(0.25 \mathrm{wt} \%$ and $0.5 \mathrm{wt} \%)$, namely, more hydrophobic polyurethanes are more effective anti-nucleators of sII gas hydrate. At the same time, increasing the WPU concentration did not improve their inhibition activity, such as different non-amide based kinetic hydrate inhibitors [44]. 


\subsection{Interfacial Tension Study}

To figure out the structure-property dependence for the designed compounds, interfacial tension (ITF) in the kerosene-water system in the presence of the WPU was studied. The water-kerosene KO-25 interfacial tension for a polyurethane solution was measured at concentrations of $0.005 ; 0.025 ; 0.25$; and $0.5 \mathrm{wt} \%$. P(VCap-VP) was tested for comparison. The data are presented in Figure 4.

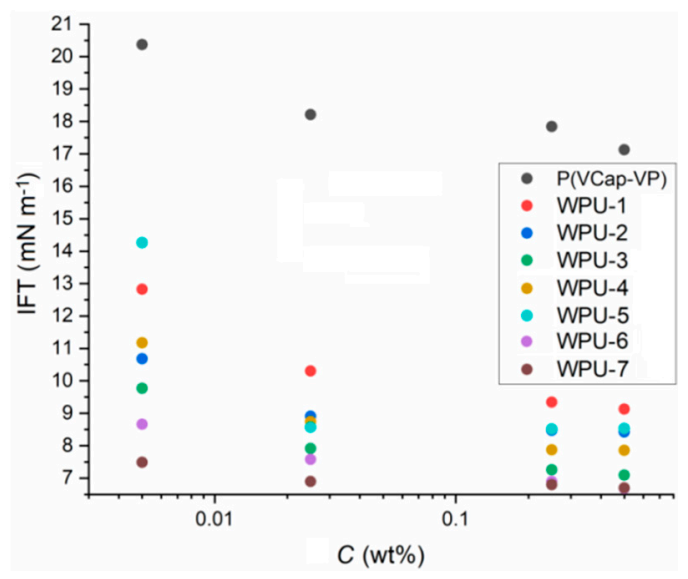

Figure 4. Interfacial tension (IFT) results for polyurethanes and P(VCap-VP) solutions.

In general, a decrease in interfacial tension takes place with an increase in concentration for all compounds. A decrease in interfacial tension with an increase in the polymers hydrophobicity was also observed. So, at a concentration of $0.25 \mathrm{wt} \%$, the compounds can be arranged in descending order of the interfacial tension value as follows: WPU-1 (monoethanolamine) $>$ WPU-2 (methyl diethanolamine $1 \times$ ) and WPU-5 (methyl diethanolamine 2.5 $\times$ ) $>$ WPU-4 (tert-butyldiethanolamine $1 \times$ ) $>$ WPU-3 (butyldiethanolamine 1×) > WPU-6 (butyldiethanolamine 2.5×) and WPU-7 (tert-butyldiethanolamine $2.5 \times$ ). Thus, the most hydrophobic polyurethanes WPU-6 and WPU-7 gave the lowest surface tension values, while the most hydrophilic ones, such as WPU-1, gave the highest values. It is well known that antiagglomerants should reduce interfacial tension to mitigate the particles adhesion to each other $[45,46]$. We speculate that either the antiagglomeration or growth inhibition activity of WPU would increase in the same order. To support this notion, Table 1 shows that there is an improvement in the hydrate growth inhibition by WPU almost exactly in the same order (see relative pressure decrease $(\alpha)$ data). These data support the assumption about the adsorption-inhibition mechanism in the case of studied polymers. Indeed, an increase in interfacial activity with the rising of hydrophobicity of polymers can make the gas-water interface more favorable for WPU molecules adsorption. In this region, hydrate formation is most likely to occur, which can be influenced by WPU molecules.

The dependence of the hydrate onset of subcooling $\Delta T_{o}$ on the interfacial tension (IFT) for the designed inhibitors is shown in Figure 5.

As one can see, with decreasing IFT, there is a trend towards an increase in $\Delta T_{0}$, i.e., the effectiveness of kinetic hydrate inhibition is improved. However, it should be noted that IFT is not a universal criterion for assessing hydrate inhibition activity. In the case of the commercial inhibitor P(VCap-VP), the IFT value is more than two times higher than that for the studied polymers, while maintaining the KHI efficiency (Figure 5). It is obvious that it depends on the structure of the polymer. It seems to be likely that this parameter can be best used within a series of homologues. However, further lengthening of the hydrocarbon side chains can lead to a lowering of the solubility of the polymer in water, which will adversely affect its KHI ability. 


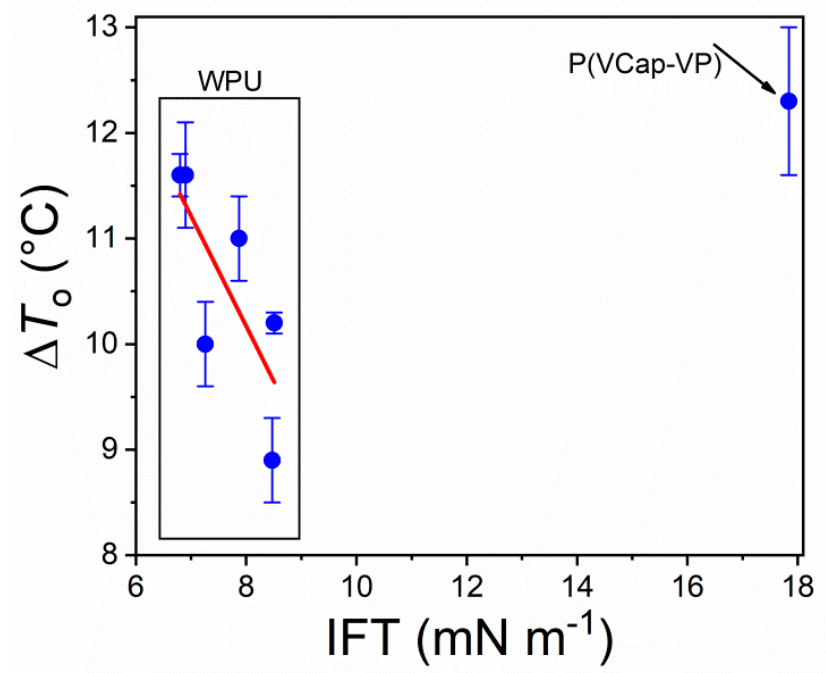

Figure 5. Dependence of the hydrate onset subcooling $\Delta T_{o}$ on the interfacial tension IFT for the samples at $0.25 \mathrm{wt} \%$.

\subsection{Electrochemical Corrosion Study}

Corrosion inhibition in the presence of WPU polyurethanes was investigated by electrochemical methods. First, the electrode potentials relative to the silver chloride electrode were analyzed. A 2M hydrochloric acid solution (model aggressive acidic environment) [47-49] without inhibitors was used as a negative control, and the same solution with the addition of a commercial inhibitor Armohib CI-28 was employed as a positive control. To obtain a more complete dataset, a commercial KHI polymer $\mathrm{P}(\mathrm{VCap}-\mathrm{VP})$ was also tested for anticorrosive activity. Open circuit potential (OCP) data and Tafel curves for all tested samples are presented in Figures 6 and 7, respectively.

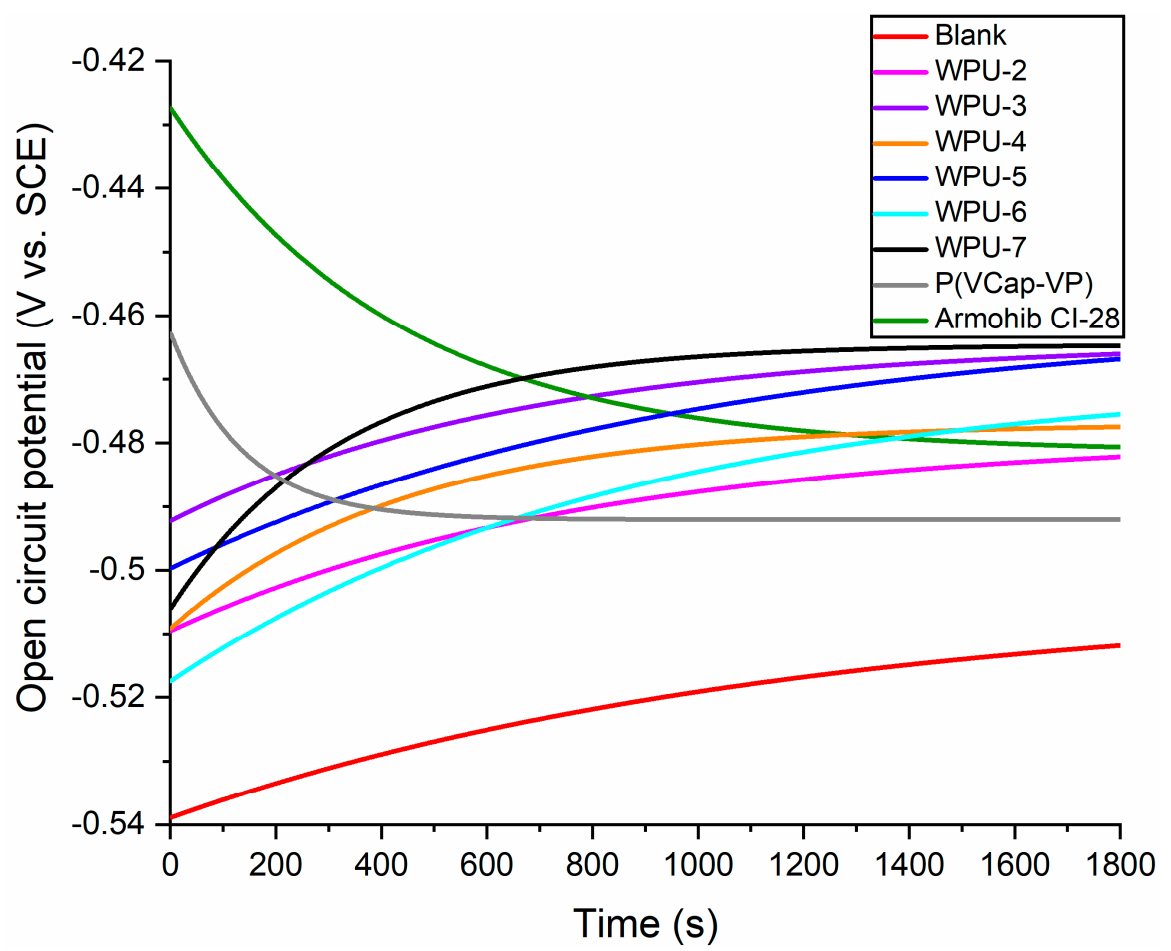

Figure 6. Variation of open circuit potential with time for $\mathrm{CS}$ in $2 \mathrm{M} \mathrm{HCl}$ solution without and with inhibitors (500 ppm); SCE-silver chloride electrode. 


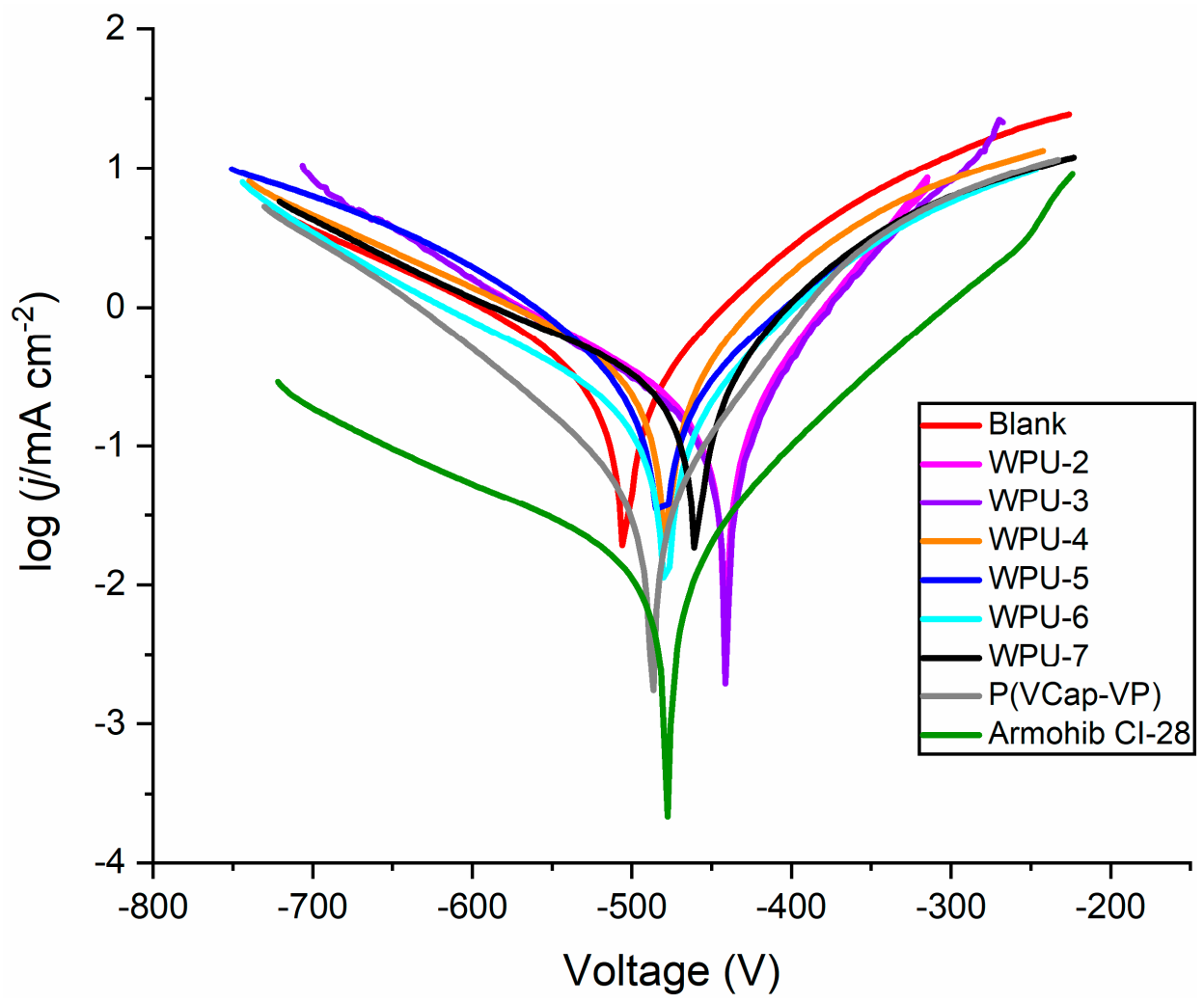

Figure 7. Tafel slopes for CS in $2 \mathrm{M} \mathrm{HCl}$ solution without and with inhibitors (500 ppm).

Electrochemical methods provide useful information on the corrosion process, such as the optimal concentration of an inhibitor and its inhibition efficiency [50]. The time dependencies of OCP for carbon steel (CS) coupon in the presence of studied substances (500 ppm) are in Figure 6. Moreover, $2 \mathrm{M} \mathrm{HCl}$ solution was used as a corrosive medium.

The steady state of $E_{\text {ocp }}$ relates to the inhibition efficiency. The observed shift of the steady-state Eocp to less negative values in the presence of WPUs may indicate the prevention of carbon steel corrosion in a studied environment. As in the case of hydrate formation, there is a trend towards an improvement in anti-corrosion properties with an increase in the polymers hydrophobicity. The WPU-7 polyurethane proved to be the best polymer for corrosion inhibition, while the WPU-2 polymer had the worst activity. It should be noted that the commercial kinetic hydrate inhibitor P(VCap-VP) exhibited good anti-corrosion properties as well under the test conditions. In the future, it is planned to perform the tests in more realistic corrosion environment $\left(\mathrm{CO}_{2}\right.$ and/or $\mathrm{H}_{2} \mathrm{~S}$ corrosion in the presence of a hydrocarbon phase).

Potentiodynamic polarization tests demonstrate the effect of an inhibitor on the kinetics of partial cathodic and anodic reactions (see Tafel curves, Figure 7). The investigated inhibitors are adsorbed on the CS surface, which causes a decrease in the rates of oxidation and reduction reactions. The maximum percentage of corrosion inhibition in the series of tested polyurethanes was equal to $83 \%$, as observed for the WPU-7 inhibitor at a concentration of $1000 \mathrm{ppm}$ (Table 2). The shift of the corrosion potential to the positive region for this inhibitor indicates that charged molecules of the inhibitor are adsorbed on the electrode surface and the effect of WPU-7 may be associated with an increase in the overvoltage of electrode reactions. The standard deviation $\sigma(\% I E)$ for the best polymers was \pm 10.87 . 
Table 2. Kinetic parameters for corrosion in the presence of WPU inhibitors at various concentrations.

\begin{tabular}{|c|c|c|c|c|c|c|c|}
\hline $\begin{array}{c}\text { Inhibitor } \\
\text { Concentration (ppm) }\end{array}$ & $\begin{array}{c}E_{o c p} \\
(\mathrm{mV} \text { vs. SCE) }\end{array}$ & $\beta a(\mathrm{~V} / \mathrm{div})$ & $\beta c(\mathrm{~V} / \mathrm{div})$ & $\begin{array}{c}E_{\text {corr }} \\
(\mathrm{mV} \text { vs. SCE) }\end{array}$ & $\begin{array}{c}I_{\text {corr }} \\
\left(\mathrm{mA} \mathrm{cm}^{-2}\right)\end{array}$ & $R p[\mathrm{Ohm}](\mathrm{m} \Omega)$ & $\% I E$ \\
\hline \multicolumn{8}{|c|}{ WPU-4 * } \\
\hline 500 & -472.7 & 0.106 & 0.192 & -478.035 & 0.3195 & 9.25 & 7.8 \\
\hline 100 & -462.3 & 0.187 & 0.206 & -518.553 & 0.7718 & 5.52 & - \\
\hline 50 & -463.2 & 0.171 & 0.210 & -512 & 0.8586 & 4.76 & - \\
\hline 0 & -511.5 & 0.118 & 0.192 & -504.618 & 0.3467 & 9.12 & - \\
\hline \multicolumn{8}{|c|}{ WPU-5 } \\
\hline 1000 & -470.6 & 0.098 & 0.209 & -459.867 & 0.213 & 13.62 & 38.6 \\
\hline 500 & -471.5 & 0.133 & 0.143 & -482.371 & 0.2943 & 10.17 & 15.1 \\
\hline 100 & -469.1 & 0.140 & 0.188 & -497.662 & 0.4293 & 8.12 & - \\
\hline 50 & -477.6 & 0.115 & 0.167 & -490.414 & 0.4333 & 7.2 & - \\
\hline 0 & -511.5 & 0.118 & 0.192 & -504.618 & 0.3467 & 9.12 & - \\
\hline \multicolumn{8}{|c|}{ WPU-6 } \\
\hline 1000 & -487.1 & 0.101 & 0.259 & -440.457 & 0.1468 & 10.85 & 57.7 \\
\hline 500 & -470.8 & 0.097 & 0.167 & -478.511 & 0.2916 & 18.16 & 15.9 \\
\hline 100 & -454.7 & 0.108 & 0.189 & -476.808 & 0.3738 & 8.004 & - \\
\hline 50 & -457.7 & 0.087 & 0.128 & -488.887 & 0.4590 & 49.16 & - \\
\hline 0 & -511.5 & 0.118 & 0.192 & -504.618 & 0.3467 & 9.12 & - \\
\hline \multicolumn{8}{|c|}{ WPU-7 } \\
\hline 1000 & -487.1 & 0.088 & 0.177 & -464.927 & 0.0587 & 43.38 & 83.1 \\
\hline 500 & -460.8 & 0.090 & 0.205 & -459.099 & 0.1024 & 11.42 & 70.5 \\
\hline 100 & -462.6 & 0.138 & 0.179 & -497.252 & 0.1473 & 9.52 & 57.5 \\
\hline 50 & -464.2 & 0.090 & 0.154 & -486.421 & 0.1668 & 12.91 & 51.9 \\
\hline 0 & -511.5 & 0.118 & 0.192 & -504.618 & 0.3467 & 9.12 & - \\
\hline \multicolumn{8}{|c|}{ P(VCap-VP) } \\
\hline 1000 & -493.2 & 0.072 & 0.111 & -491.581 & 0.0374 & 50.9 & 89.2 \\
\hline 500 & -491.6 & 0.075 & 0.114 & -487.208 & 0.0519 & 37.7 & 85.0 \\
\hline 100 & -494.7 & 0.079 & 0.118 & -483.531 & 0.0889 & 23.2 & 74.4 \\
\hline 50 & -497.7 & 0.074 & 0.107 & -492.829 & 0.0539 & 32.2 & 84.5 \\
\hline 0 & -511.5 & 0.118 & 0.192 & -504.618 & 0.3467 & 9.12 & - \\
\hline \multicolumn{8}{|c|}{ Armohib CI-28 } \\
\hline 1000 & -458.1 & 0.076 & 0.243 & -449.846 & 0.0313 & 80.3 & 91.0 \\
\hline 500 & -483.1 & 0.09 & 0.208 & -478.083 & 0.0138 & 198.5 & 96.0 \\
\hline 100 & -484 & 0.095 & 0.204 & -471.736 & 0.0235 & 119.5 & 93.2 \\
\hline 50 & -491 & 0.091 & 0.10 & -484.843 & 0.0289 & 89.1 & 91.7 \\
\hline 0 & -511.5 & 0.118 & 0.192 & -504.618 & 0.3467 & 9.12 & - \\
\hline
\end{tabular}

The addition of inhibitors also affects the limiting stages of reactions (dissolution of anodic carbon steel and cathodic reactions of hydrogen evolution), which manifests itself in a change in the slopes of the curves in the region of anodic polarization. The observed changes in the slopes are insignificant, which indicates that these compounds can be classified as mixed type inhibitors, i.e., both anodic and cathodic corrosion inhibitors.

Table 2 demonstrates corrosion current density $\left(i_{\text {corr }}\right)$, corrosion potentials $\left(E_{c o r r}\right)$, cathodic slope $(\beta c)$, anodic slope $(\beta a)$, polarization resistance $(R p)$ and inhibition efficiency in $2 \mathrm{M} \mathrm{HCl}$ solution containing 50, 100, 500, and 1000 ppm of WPU compared to blank system. From Table 2, the dependence of anti-corrosion properties on the structure of polyurethanes is especially clearly visible. Thus, with an increase in the hydrophobicity of polymers in the Me-Bu-tBu row, a sharp retardation in the corrosion rate is observed. For WPU-5, WPU-6, and WPU-7 characterized with an increased content of substituted diethanolamine (2.5×), \%IE at a concentration of $1000 \mathrm{ppm}$ increases from $39 \%$ to $58 \%$ 
and $83 \%$, respectively. In the case of a low content of substituted diethanolamine in the polymer, only polyurethane WPU-4 at a concentration of $500 \mathrm{ppm}$ showed a slight decrease in corrosion rate of $8 \%$ (in the acidic environment a precipitation occurred at a concentration of $1000 \mathrm{ppm}$ ). The commercial inhibitor Armohib CI-28 in the concentration range from $50 \mathrm{ppm}$ to $1000 \mathrm{ppm}$ reduced the corrosion rate with an efficiency of over $90 \%$.

It may be assumed that the polar functional groups and charged parts of the WPU act as binding centers while the hydrophobic substituents contribute to the formation of a protective barrier [51-54]. In an $\mathrm{HCl}$ medium, the tertiary amine will partially neutralize the acid, forming a salt with it. However, even if this factor does matter, its contribution is noticeably less than that of hydrophobic substituents, since a decrease in the content of the acid fragment does not lead to a decrease in the anticorrosive properties of designed polymers.

\subsection{Weight-Loss Corrosion Study}

According to the whole data set, polyurethane WPU-7 can be attributed to one of the most promising in a series of synthesized compounds. Thus, the efficiency of WPU-7 as corrosion inhibitor was additionally checked by weight-loss technique. The same $\mathrm{CS}$ and $2 \mathrm{M} \mathrm{HCl}$ solution were used. Tests reveal that WPU-7 is capable of inhibiting corrosion (see data on inhibition efficiency (\%IE $E_{w}$, Equation (4)) in Table 3). It has been shown that the corrosion inhibition efficiency is more than $90 \%$ even at a concentration of $50 \mathrm{ppm}$.

Table 3. Inhibition efficiency, corrosion rate, and surface coverage of WPU-7 at different concentrations in $2 \mathrm{M} \mathrm{HCl}$.

\begin{tabular}{ccccc}
\hline $\begin{array}{c}\text { Concentration } \\
(\mathbf{p p m})\end{array}$ & $\begin{array}{c}\text { Weight Loss } \\
(\mathbf{g})\end{array}$ & $\begin{array}{c}\text { Corrosion Rate } \\
(\mathbf{m m} / \mathbf{y})\end{array}$ & $\begin{array}{c}\text { Surface Coverage } \\
(\boldsymbol{\theta})\end{array}$ & $\begin{array}{c}\text { Inhibition Efficiency } \\
\left(\mathbf{\%} I E_{\boldsymbol{w}}\right)\end{array}$ \\
\hline Blank & 0.5581 & 9.19 & - & - \\
\hline 50 & 0.0266 & 0.44 & 0.90 & 90.1 \\
\hline 100 & 0.0251 & 0.41 & 0.91 & 90.6 \\
\hline Armohib CI-28 100 ppm & 0.0035 & 0.058 & 0.99 & 98.7 \\
\hline
\end{tabular}

It should be noted that these data are inconsistent with those in Table 2, which shows relatively low corrosion inhibition properties of the polymer at these concentrations. However, one should remember that these methods are fundamentally different from each other, and this may impose certain limitations in comparing the results obtained on their basis [55]. Nonetheless, it can be supposed that when WPU-7 is used at concentrations above 1000 ppm, i.e., as a KHI, it will definitely exhibit good anti-corrosion properties.

\subsection{Biodegradability of WPU}

The widespread use of hydrate and corrosion inhibitors, especially on the shelf, imposes certain requirements on them, namely eco-friendly properties and biodegradability. Preliminary study of the biodegradability of WPU-6 and WPU-7 was determined according to the Shurui Xu's work [56] (Table 4 and Figure 8). This method is based on the calculation of the $\mathrm{BOD}_{\mathrm{t}} / \mathrm{COD}_{\mathrm{cr}}$ ratio (biochemical oxygen demand after a certain time $t$ in days and chemical oxygen demand, respectively). This indicator directly correlates with the biodegradation of the test substance, i.e., the higher the given value, the better its biodegradation. For readily biodegradable, partially biodegradable, poorly biodegradable and hardly biodegradable substances the $\mathrm{BOD}_{\mathrm{t}} / \mathrm{COD}_{\mathrm{cr}}$ ratio are $>0.45,>0.3,<0.3$, and $<0.2$, respectively. 
Table 4. Biodegradation of WPU-6, WPU-7, and P(VCap-VP) based on the ratio of biochemical oxygen demand after 5,15 and 30 days $\left(\mathrm{BOD}_{\mathrm{t}}\right)$ and chemical oxygen demand $\left(\mathrm{COD}_{\mathrm{cr}}\right)$.

\begin{tabular}{|c|c|c|c|c|}
\hline Inhibitor & Time (Days) & BOD $_{t}\left(\mathrm{mg} \mathrm{L}^{-1}\right)$ & $\mathrm{COD}_{\mathrm{cr}}\left(\mathrm{mg} \mathrm{L}^{-1}\right)$ & Degradation (\%) \\
\hline \multirow{3}{*}{ P(VCap-VP) } & 5 & $105 \pm 23$ & \multirow{3}{*}{$690 \pm 7$} & $15.2 \pm 3.5$ \\
\hline & 15 & $166 \pm 22$ & & $23.7 \pm 3.3$ \\
\hline & 30 & $173 \pm 21$ & & $25.1 \pm 3.3$ \\
\hline \multirow{3}{*}{ WPU-6 } & 5 & $68 \pm 23$ & \multirow{3}{*}{$700 \pm 6$} & $9.6 \pm 3.4$ \\
\hline & 15 & $138 \pm 22$ & & $19.7 \pm 3.3$ \\
\hline & 30 & $164 \pm 20$ & & $23.4 \pm 3.1$ \\
\hline \multirow{3}{*}{ WPU-7 } & 5 & $109 \pm 22$ & \multirow{3}{*}{$678 \pm 7$} & $16.1 \pm 3.4$ \\
\hline & 15 & $182 \pm 21$ & & $26.8 \pm 3.3$ \\
\hline & 30 & $199 \pm 20$ & & $29.4 \pm 3.3$ \\
\hline
\end{tabular}

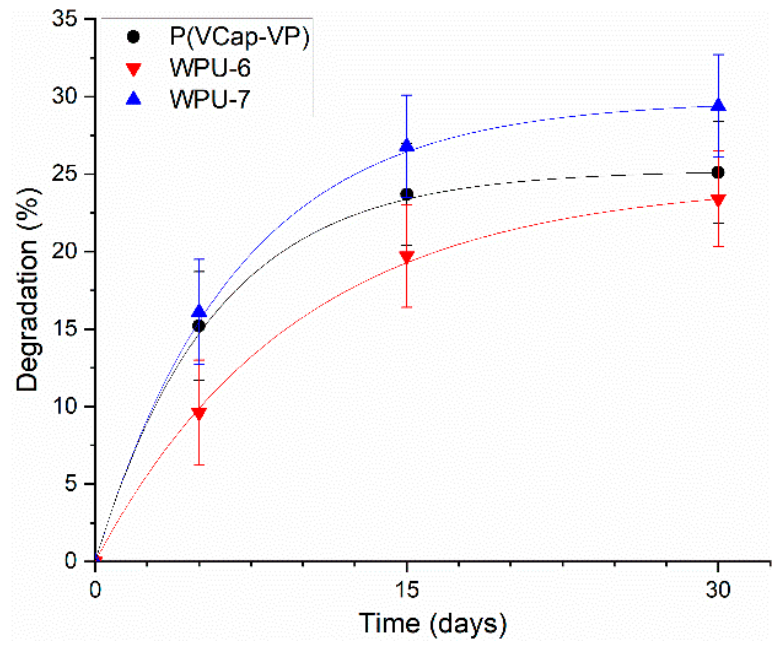

Figure 8. Biodegradation trends for WPU-6, WPU-7, and P(VCap-VP).

One can see that WPU-6 and WPU-7 belongs to the poorly biodegradable compounds, since the $\mathrm{BOD}_{\mathrm{t}} / \mathrm{COD}_{\mathrm{cr}}$ value is within 0.2 and 0.3 (Table 4). At the same time, commercial KHI P(VCap-VP) is poorly degradable as well. It can be assumed that the ability of WPU to biodegrade under the action of microorganisms is due to the presence of ester bonds in their structure.

\section{Materials and Methods}

\subsection{Materials}

All reagents were obtained from commercial sources and were used without further purification unless otherwise stated. Deionized water prepared by Arium mini plus ultra-pure water system (Sartorius, Goettingen, Germany) to achieve resistivity $18.20 \mathrm{M} \Omega \cdot \mathrm{cm}$ at $25^{\circ} \mathrm{C}$ was used in all experiments. Commercial KHI Luvicap 55 W (BASF, Ludwigshafen, Germany) and corrosion inhibitor Armohib CI-28 (AkzoNobel, Amsterdam, Netherlands) were used for comparison. The former one is copolymer of $N$-vinyl caprolactam and $N$-vinyl pyrrolidone (hereinafter P(VCap-VP)) with molar ratio of 1:1 and molecular mass of $2-8 \mathrm{kDa}$. The latter one belongs to the class of fatty acid imidazolines. Binary mixture of $4.34 \mathrm{~mol} \% \mathrm{C}_{3} \mathrm{H}_{8}+95.66 \mathrm{~mol}^{2} \mathrm{CH}_{4}$ was employed as hydrate-forming gas. This mixture forms the hydrate of cubic structure II (sII) which is common one encountered in the field. 


\subsection{Preparation of Waterborne Polyurethanes}

A waterborne polyurethane (WPU) was synthesized according to our previous work [25]. Briefly, the polyethylene glycol 400 (PEG 400) and 2,2-bis(hydroxymethyl)propionic acid (DMPA) were mixed for $30 \mathrm{~min}$ at $70{ }^{\circ} \mathrm{C}$ to make a homogeneous blend. Then, isophorone diisocyanate (IPDI) was added and the polymerization was followed at $85^{\circ} \mathrm{C}$ for $2 \mathrm{~h}$; tetrahydrofuran (THF) was used to reduce the solution viscosity. After $2 \mathrm{~h}, \mathrm{~N}$-substituted diethanolamine was dosed to the system and the reaction was continued for $5 \mathrm{~h}$ at $85^{\circ} \mathrm{C}$. At the end of polymerization, the temperature of the reaction mixture was decreased to $25^{\circ} \mathrm{C}$ followed by triethylamine (TEA, 1.2 equivalents on acid) addition to neutralize the solution. Finally, deionized water was added to produce the WPU solution (Scheme 1). The average molecular weight of all synthesized polymers was $\sim 4 \mathrm{kDa}$. In the case of WPU-7, partial formation of higher molecular weight polyurethanes was observed ( 16 and $\sim 24 \mathrm{kDa})$. The structure of the WPUs was characterized by ${ }^{1} \mathrm{H}-{ }^{13} \mathrm{C}-\mathrm{NMR}$, and FT-IR. Methods of synthesis and analytical characterization of all newly synthesized compounds are detailed in the Electronic Supplementary Materials.

\subsection{Characterization Methods}

${ }^{1} \mathrm{H}$ - and ${ }^{13} \mathrm{C}-\mathrm{NMR}$ spectra were recorded on an AVANCE 400 (Bruker, Karlsruhe, Germany) at operating frequency of 400 and $101.56 \mathrm{MHz}$, respectively. Chemical shifts were measured with reference to the residual protons of the solvent $\left(\mathrm{CDCl}_{3}\right)$. The following abbreviations are used to describe coupling: $\mathrm{br} \mathrm{s}=$ broad singlet, $\mathrm{br} \mathrm{t}=$ broad triplet, $\mathrm{br} \mathrm{q}=$ broad quartet, $\mathrm{br} \mathrm{m}=$ broad multiplet. FT-IR spectra (600-4000 $\mathrm{cm}^{-1}$ ) were acquired using a Vertex 70 FT-IR spectrometer (Bruker, Germany) equipped with single reflection ZnSe crystal ATR accessory (MIRacle, PIKE Technologies, Madison, WI, USA).

\subsection{Sapphire Rocking Cells (RCS6)}

A Sapphire Rocking Cell RCS6 rig (PSL Systemtechnik, Osterode am Harz, Germany) was employed to assess the hydrate inhibition activity of synthesized polymers. It is equipped with six leuco sapphire cells placed in the thermostatic bath. Temperature and pressure sensors are calibrated with Fluke 1524 with the secondary reference PRT 5616-12 (Everett, WA, USA; measurement error is $\pm 0.011^{\circ} \mathrm{C}$ ) and Fluke $7175000 \mathrm{G}$ (USA, measurement error is \pm 0.17 bar) respectively. A stainless-steel ball is placed in each cell to agitate the solution.

The aqueous solutions of the prepared inhibitors as well as $\mathrm{P}(\mathrm{VCap}-\mathrm{VP})$ were tested at concentrations of 0.25 and $0.5 \mathrm{wt} \%$. Hydrate-forming gas $\left(4.34 \mathrm{~mol} \% \mathrm{C}_{3} \mathrm{H}_{8}+95.66 \mathrm{~mol} \% \mathrm{CH}_{4}\right)$ was supplied in the cells preliminary purged three times with the same mixture (up to 10 bar). An experimental run started with maintaining the system at $18.5^{\circ} \mathrm{C}$ and 59.3 bar for $1 \mathrm{~h}$, followed by cooling at $1{ }^{\circ} \mathrm{C} \mathrm{h}^{-1}$ from $18.5^{\circ} \mathrm{C}$ to $-0.5^{\circ} \mathrm{C}$. After the cooling stage, the cells were heated up to $33^{\circ} \mathrm{C}$ and held for $3 \mathrm{~h}$ for the hydrate complete dissociation and prevention of the "memory effect" in the subsequent cooling cycle. The cells were rocked by an angle of $\pm 45^{\circ}$ with a frequency of $10 \mathrm{~min}^{-1}$ during the whole experiment. Detailed description of the equipment and experimental procedure is described elsewhere [40]. Relative pressure decrease was used to assess the part of gas trapped in the hydrate state at the end of the cooling stage. It was calculated according to Equation (1):

$$
\alpha=\frac{P_{h}-P_{r}}{P_{h}} \cdot 100 \%
$$

where $P_{h}$-hypothetical pressure (if gas hydrate would be absent), which is determined by linear approximation of the pressure to a certain temperature, $P_{r}$-actual pressure in the cell at the same temperature. 


\subsection{The Study of Interfacial Tension}

The effect of polyurethanes on the reduction of interfacial tension (IFT) was studied in a system of water-kerosene KO-25 (illuminating kerosene; light hydrocarbon liquid; see Electronic Supplementary Materials for more details). The IFT measurements were carried out with an SDT tensiometer (Kruss, Hamburg, Germany) using the spinning drop method at solute concentrations in aqueous phase of $0.005 ; 0.025 ; 0.25$ and $0.5 \mathrm{wt} \%$. IFT is measured by achieving equilibrium between the surface and the centrifugal forces according to the Vonnegut model. The measurements were carried out at $20^{\circ} \mathrm{C}$. To form an elongated droplet the capillary rotation speed 14,000 $\mathrm{g} \mathrm{rpm}$ was used. Each measurement lasted $30 \mathrm{~min}$.

\subsection{Electrochemical Measurements}

Carbon steel (CS) coupons with dimensions of $2.54 \times 5.08 \mathrm{~cm}$ and composition of (wt\%) C, 0.24; $\mathrm{Si}, 0.37 ; \mathrm{Mn}, 0.65 ; \mathrm{Cu}, 0.25 ; \mathrm{Ni}, 0.25 ; \mathrm{As}, 0.08 ; \mathrm{S}, 0.045 ; \mathrm{P}, 0.035$ and $\mathrm{Fe}, 98.08$ were washed 5 times with water and ethanol. Emery papers $(800,1000$, and 1200 grades) were used to polish the surface of CS followed by its rewashing with distilled water and ethanol. The tests were conducted in the electrochemical three-electrode cell in static mode under the natural aeration at room temperature $(22 \pm 2)^{\circ} \mathrm{C}$ in $2 \mathrm{M} \mathrm{HCl}$ solution, with and without an inhibitor. The whole experiment was carried out in deionized water. The surface area of the working electrode was $10 \mathrm{~cm}^{2}(50 \times 25 \times 1 \mathrm{~cm})$ with the waterline isolated by varnish. The main reference electrode was EVL-IM3 type silver chloride one. The auxiliary reference electrode was made of the same material as the working one; the auxiliary one was a platinum electrode. Before testing procedures, a sample's surface was cleaned off grease by soda, distilled water, and ethanol followed by drying at room temperature.

Electrochemical measurements were carried out by ZIVE SP2 workstation. After immersion of samples in solution, the values of open-circuit potential (EOCP) were acquired at least for one hour. If the potential value variation did not exceed $30 \mathrm{mV}$ over the last $0.5 \mathrm{~h}$, the value of the potential at the end of immersion was taken as EOCP. Potentiodynamic polarization was carried out by sweeping the working electrode potential $\pm 250 \mathrm{mV}$ away from the EOCP at $1 \mathrm{mV} \mathrm{s}^{-1}$ scan rate. Anodic and cathodic polarization curves showing the correlation between the potential of the studied electrode and the current density upon polarization from an external direct current source were registered. Then the kinetic parameters of reaction were determined, namely corrosion potential and current, the values of Tafel equation parameters (Tafel slopes), and corrosion rate as well. To determine the corrosion resistance the linear polarization curves were recorded by sweeping the working electrode potential $\pm 20 \mathrm{mV}$ away from the EOCP at $0.5 \mathrm{mV} \mathrm{s}^{-1}$ scan rate. The corrosion current density $\left(I_{\text {corr }}\right)$ and $E_{c o r r}$ were obtained by extrapolation of the Tafel lines. The inhibition efficiency (\%IE) was computed as follows:

$$
\% I E=\left(1-\frac{I_{\text {corr }}}{I_{\text {corr }}^{\circ}}\right) \times 100 \%
$$

where $I_{\text {corr }}^{\circ}$ is the corrosion current density for blank system (2M HCl solution) and $I_{\text {corr }}$ is the corrosion current density with an inhibitor.

\subsection{Corrosion Weight-Loss Experiments}

The same carbon steel coupons (CS) and their preparation procedure (washing and polishing) were used. The high-resolution analytical balance $(0.00001 \mathrm{~g})$ was employed for weighing the initial $\left(W_{0}\right)$ final $\left(W_{24}\right)$ masses of CS. Experiments were performed in the acid solution $(2 \mathrm{M} \mathrm{HCl})$ at different concentrations of inhibitor for $24 \mathrm{~h}$ in open glass vials at $25^{\circ} \mathrm{C}$. Before the re-weighing, the steel coupons were washed three times with ethanol and distilled water. The experiment was repeated 
three times to ensure repeatability of results. The corrosion rate $(\mathrm{mm} / \mathrm{y})$, inhibition efficiency $\left(\% I E_{w}\right)$, and surface coverage $(\theta)$ were calculated using the following equations [57].

$$
\begin{aligned}
C R & =\frac{8.76 \times 10^{4} \times \Delta m}{s \times t \times p} \\
\% I E_{w} & =\frac{C R_{0}-C R_{i n h}}{C R_{0}} \times 100 \% \\
\Theta & =\frac{C R_{0}-C R_{i n h}}{C R_{0}}
\end{aligned}
$$

where $\Delta m(\mathrm{~g}), s\left(\mathrm{~cm}^{2}\right), t(\mathrm{~h})$, and $\rho\left(\mathrm{g} \mathrm{cm}^{-3}\right)$ are the average value of the weight loss of CS, the total area of the CS, the corrosion time and the density of the CS, respectively.

\section{Conclusions}

Previously, we described a class of water-soluble polyurethanes as promising dual-function inhibitors. To study this class of polymers in more detail, the presented work investigated the dependence of their activity as hydrate and corrosion inhibitors on the polymer structure. To synthesize polyurethanes of various hydrophobicity $N$-substituted diethanolamines (methyl, $n$-butyl, and tert-butyl) were used. It was proved that the dual inhibiting properties of designed polyurethanes significantly increase with a raise in their hydrophobicity. The kinetic hydrate inhibition was assessed using rocking cells, the anticorrosive properties were determined electrochemically and gravimetrically in an environment of $2 \mathrm{M} \mathrm{HCl}$. Some of the synthesized polymers worked as dual-acting inhibitors, showing nearly the same efficiency compared to commercial reagents (WPU-6 and WPU-7 at $0.25 \mathrm{wt} \%$ ). Since the BOD $/ \mathrm{COD}_{\mathrm{cr}}$ value for WPU-6 and WPU-7 turned out to be 0.234 and 0.294 respectively, these polyurethanes, as well as the commercial kinetic hydrate inhibitor, belong to poorly biodegradable substances. Taking into account the concentrations at which the polyurethanes demonstrate anti-hydrate and anti-corrosion activity, employment of WPU may optimize the consumption of oilfield reagents.

In general, this class of polymers is promising for the development of multifunctional oilfield reagents, since it is relatively easy to impart the desired properties to such polyurethanes by the correct selection of monomers in the synthesis. As the size of the hydrophobic fragment of polyurethanes plays an important role in the performance of the WPUs as KHI and corrosion inhibitors, the determination of the hydrate inhibition activity of similar polyurethanes with cycloalkyl and lactam ring fragments is of particular interest. Selection of such promising monomers for polyurethanes to obtain appropriate water-solubility, inhibition properties, stability, safety, etc., is the subject of our further studies.

Supplementary Materials: The following are available online, General information about NMR and FT-IR Spectroscopy as well as characteristics of kerosene KO-25, methods for the preparation of waterborne polyurethanes, estimation of their molecular weights by polyacrylamide gel electrophoresis and ${ }^{1} \mathrm{H}-\mathrm{NMR},{ }^{13} \mathrm{C}-\mathrm{NMR}$, and FT-IR spectra of WPU-2-WPU-7 are described.

Author Contributions: Conceptualization, R.S.P., M.A.V., and M.A.K.; methodology, R.S.P., A.P.S., and A.S.S.; validation, R.S.P., M.A.V., A.P.S., and A.S.S.; data curation, R.S.P., A.P.S., and A.S.S.; writing-original draft preparation, R.S.P.; writing-review and editing, R.S.P., M.A.V., M.A.K., A.P.S., and A.S.S.; formal analysis, M.A.V., A.P.S., and A.S.S.; investigation, R.S.P., S.A.N., K.R.K., Y.F.Z., V.V.Y., S.S.V., S.R., L.R.V., A.P.S., R.I.M., and A.S.S.; resources, M.A.V.; visualization, R.S.P., A.P.S., and A.S.S.; supervision, M.A.V. and M.A.K.; project administration, R.S.P. and A.S.S.; funding acquisition, M.A.V. and M.A.K. All authors have read and agreed to the published version of the manuscript.

Funding: The reported study was funded by RFBR and The Research Council of Norway according to the research project № 20-55-20010. The work of A.P.S. and R.I.M. (rocking cells experiments) was supported by the State Assignment FSZE-2020-0007 (project 0768-2020-0007) in scientific activities in Gubkin University.

Conflicts of Interest: The authors declare no conflict of interest. 


\section{References}

1. Sloan, E.D., Jr. Fundamental principles and applications of natural gas hydrates. Nature 2003, 426, 353. [CrossRef] [PubMed]

2. Hassanpouryouzband, A.; Joonaki, E.; Farahani, M.V.; Takeya, S.; Ruppel, C.; Yang, J.; English, N.J.; Schicks, J.M.; Edlmann, K.; Mehrabian, H.; et al. Gas hydrates in sustainable chemistry. Chem. Soc. Rev. 2020, 49, 5225-5309. [CrossRef] [PubMed]

3. Srivastava, V.; Eaton, M.W.; Koh, C.A.; Zerpa, L.E. Quantitative Framework for Hydrate Bedding and Transient Particle Agglomeration. Ind. Eng. Chem. Res. 2020, 59, 12580-12589. [CrossRef]

4. Raja, P.B.; Ismail, M.; Ghoreishiamiri, S.; Mirza, J.; Ismail, M.C.; Kakooei, S.; Rahim, A.A. Reviews on corrosion inhibitors: A short view. Chem. Eng. Commun. 2016, 203, 1145-1156. [CrossRef]

5. Zhu, Y.; Free, M.L.; Woollam, R.; Durnie, W. A review of surfactants as corrosion inhibitors and associated modeling. Prog. Mater. Sci. 2017, 90, 159-223. [CrossRef]

6. Brustad, S.; Løken, K.-P.; Waalmann, J.G. Hydrate Prevention using MEG instead of MeOH: Impact of experience from major Norwegian developments on technology selection for injection and recovery of MEG. In Proceedings of the Offshore Technology Conference, Houston, TX, USA, 2-5 May 2005.

7. Moore, J.; Ver Vers, L.; Conrad, P. Understanding Kinetic Hydrate Inhibitor and Corrosion Inhibitor Interactions. In Proceedings of the Offshore Technology Conference, Houston, TX, USA, 4-7 May 2009.

8. Webber, P.A.; Jones, R.; Morales, N.; Anthony, J.; Harrington, R. Development of a Novel Kinetic Hydrate Inhibitor and Corrosion Inhibitor Package for Wet Gas Application. In Proceedings of the Offshore Technology Conference, Houston, TX, USA, 6-9 May 2013.

9. Nešić, S. Key issues related to modelling of internal corrosion of oil and gas pipelines-A review. Corros. Sci. Elsevier 2007, 49, 4308-4338. [CrossRef]

10. Seo, Y. Hydrate Inhibitors and Their Interferences in Corrosion Inhibition. Corros. Inhib. Oil Gas Ind. 2020, 407-419. [CrossRef]

11. Qasim, A.; Lal, B.; Shariff, A.M.; Ismail, M.C. Role of Ionic Liquid-Based Multipurpose Gas Hydrate and Corrosion Inhibitors in Gas Transmission Pipeline. In Nanotechnology-Based Industrial Applications of Ionic Liquids; Inamuddin, Asiri, A.M., Eds.; Springer International Publishing: Basel, Switzerland, 2020; pp. 221-244.

12. Qasim, A.; Khan, M.S.; Lal, B.; Shariff, A.M. A perspective on dual purpose gas hydrate and corrosion inhibitors for flow assurance. J. Pet. Sci. Eng. 2019, 183, 106418. [CrossRef]

13. Umoren, S.A.; Obot, I.B. Polyvinylpyrollidone and polyacrylamide as corrosion inhibitors for mild steel in acidic medium. Surf. Rev. Lett. 2008, 15, 277-286. [CrossRef]

14. Sheng, Q.; Silveira, K.C.D.; Tian, W.; Fong, C.; Maeda, N.; Gubner, R.; Wood, C.D. Simultaneous hydrate and corrosion inhibition with modified poly (vinyl caprolactam) polymers. Energy Fuels 2017, 31, 6724-6731. [CrossRef]

15. Javadian, S.; Yousefi, A.; Neshati, J. Synergistic effect of mixed cationic and anionic surfactants on the corrosion inhibitor behavior of mild steel in 3.5\% NaCl. Appl. Surf. Sci. 2013, 285, 674-681. [CrossRef]

16. Haidera, J.; Saeed, S.; Qyyum, M.A.; Kazmi, B.; Ahmad, R.; Muhammad, A.; Lee, M. Simultaneous capture of acid gases from natural gas adopting ionic liquids: Challenges, recent developments, and prospects. Renew. Sustain. Energy Rev. 2020, 123, 109771. [CrossRef]

17. Pretti, C.; Chiappe, C.; Pieraccini, D.; Gregori, M.; Abramo, F.; Monnia, G.; Intorrec, L. Acute toxicity of ionic liquids to the zebrafish (Danio rerio). Green Chem. 2006, 8, 238-240. [CrossRef]

18. Gathergood, N.; Garcia, M.T.; Scammells, P.J. Biodegradable ionic liquids: Part I. Concept, preliminary targets and evaluation. Green Chem. 2004, 6, 166-175. [CrossRef]

19. Garcia, M.T.; Gathergood, N.; Scammells, P.J. Biodegradable ionic liquids Part II. Effect of the anion and toxicology. Green Chem. 2005, 7, 9-14. [CrossRef]

20. Kelland, M.A. A review of kinetic hydrate inhibitors from an environmental perspective. Energy Fuels 2018, 32, 12001-12012. [CrossRef]

21. Bavoh, C.B.; Lal, B.; Osei, H.; Sabil, K.M.; Mukhtar, H. A review on the role of amino acids in gas hydrate inhibition, $\mathrm{CO}_{2}$ capture and sequestration, and natural gas storage. J. Nat. Gas Sci. Eng. 2019, 64, 52-71. [CrossRef] 
22. Otake, T.; Taniguchi, T.; Furukawa, Y.; Kawamura, F.; Nakazawa, H.; Kakegawa, T. Stability of Amino Acids and Their Oligomerization under High-Pressure Conditions: Implications for Prebiotic Chemistry. Astrobiology 2011, 11, 799-813. [CrossRef]

23. Parr, M.D.; Bertch, K.E.; Rapp, R.P. Amino acid stability and microbial growth in total parenteral nutrient solutions. Am. J. Hosp. Pharm. 1985, 42, 2688-2691. [CrossRef]

24. Park, J.; Kim, H.; Sheng, Q.; Wood, C.D.; Seo, Y. Kinetic hydrate inhibition performance of poly (vinyl caprolactam) modified with corrosion inhibitor groups. Energy Fuels 2017, 31, 9363-9373. [CrossRef]

25. Farhadian, A.; Kudbanov, A.; Varfolomeev, M.A.; Dalmazzone, D. Waterborne Polyurethanes as a New and Promising Class of Kinetic Inhibitors for Methane Hydrate Formation. Sci. Rep. 2019, 9, 9797. [CrossRef] [PubMed]

26. Farhadian, A.; Varfolomeev, M.A.; Kudbanov, A.; Gallyamova, S.R. A new class of promising biodegradable kinetic/anti-agglomerant methane hydrate inhibitors based on castor oil. Chem. Eng. Sci. 2019, 206, 507-517. [CrossRef]

27. Farhadian, A.; Varfolomeev, M.A.; Rezaeisadat, M.; Semenov, A.P.; Stoporev, A.S. Toward a bio-based hybrid inhibition of gas hydrate and corrosion for flow assurance. Energy 2020, 210, 118549. [CrossRef]

28. Farhadian, A.; Varfolomeev, M.A.; Shaabani, A.; Nasiri, S.; Vakhitov, I.; Zaripova, Y.F.; Yarkovoi, V.V.; Sukhov, A.V. Sulfonated chitosan as green and high cloud point kinetic methane hydrate and corrosion inhibitor: Experimental and theoretical studies. Carbohydr. Polym. 2020, 236, 116035. [CrossRef]

29. Howard, G.T. Biodegradation of polyurethane: A review. Int. Biodeterior. Biodegrad. 2002, 49, $245-252$. [CrossRef]

30. Luo, S.; Yang, K.; Zhong, Z.; Wu, X.; Ren, T. Facile preparation of degradable multi-arm-starbranched waterborne polyurethane with bio-based tannic acid. Rsc Adv. 2018, 8, 37765-37773. [CrossRef]

31. Kelland, M.A.; Dirdal, E.G.; Zhang, Q. High cloud point polyvinylaminals as non-amide-based kinetic gas hydrate inhibitors. Energy Fuels 2020, 34, 8301-8307. [CrossRef]

32. Dirdal, E.G.; Kelland, M.A. Does the Cloud Point Temperature of a Polymer Correlate with Its Kinetic Hydrate Inhibitor Performance? Energy Fuels 2019, 33, 7127-7137. [CrossRef]

33. Kelland, M.A.; Moi, N.; Howarth, M. Breakthrough in synergists for kinetic hydrate inhibitor polymers, hexaalkylguanidinium salts: Tetrahydrofuran hydrate crystal growth inhibition and synergism with polyvinylcaprolactam. Energy Fuels 2013, 27, 711-716. [CrossRef]

34. Kelland, M.A. History of the Development of Low Dosage Hydrate Inhibitors. Energy Fuels 2006, 20, 825-847. [CrossRef]

35. Kelland, M.A. A Review of Kinetic Hydrate Inhibitors: Tailor-Made Water-Soluble Polymers for Oil and Gas Industry Applications. Adv. Mater. Sci. Res. 2011, 8, 171-210.

36. Zhang, Q.; Kelland, M.A.; Ajiro, H. Polyvinylsulfonamides as Kinetic Hydrate Inhibitors. Energy Fuels 2020, 34, 2230-2237. [CrossRef]

37. Liu, J.; Wang, H.; Guo, J.; Chen, G.; Zhong, J.; Yan, Y.; Zhang, J. Molecular insights into the kinetic hydrate inhibition performance of Poly (N-vinyl lactam) polymers. J. Nat. Gas Sci. Eng. 2020, 83, 103504. [CrossRef]

38. Zanota, M.L.; Dicharry, C.; Graciaa, A. Hydrate plug prevention by quaternary ammonium salts. Energy Fuels 2005, 19, 584-590. [CrossRef]

39. Bui, T.; Phan, A.; Monteiro, D.; Lan, Q.; Ceglio, M.; Acosta, E.; Krishnamurthy, P.; Striolo, A. Evidence of structure-performance relation for surfactants used as antiagglomerants for hydrate management. Langmuir 2017, 33, 2263-2274. [CrossRef]

40. Semenov, A.P.; Mendgaziev, R.I.; Stoporev, A.S.; Kuchierskaya, A.A.; Novikov, A.A.; Vinokurov, V.A. Gas hydrate nucleation and growth in the presence of water-soluble polymer, nonionic surfactants, and their mixtures. J. Nat. Gas Sci. Eng. 2020, 82, 103491. [CrossRef]

41. Moon, C.; Hawtin, R.W.; Rodger, P.M. Nucleation and control of clathrate hydrates: Insights from simulation. Faraday Discuss. 2007, 136, 367-382. [CrossRef]

42. Del Villano, L.; Kelland, M.A. Tetrahydrofuran hydrate crystal growth inhibition by hyperbranched poly (ester amide)s. Chem. Eng. Sci. 2009, 64, 3197-3200. [CrossRef]

43. Sa, J.H.; Kwak, G.H.; Lee, B.R.; Park, D.H.; Han, K.; Lee, K.H. Hydrophobic amino acids as a new class of kinetic inhibitors for gas hydrate formation. Sci. Rep. 2013, 3, 2428. [CrossRef]

44. Zhang, Q.; Kelland, M.A.; Lewoczko, E.M.; Bohannon, C.A.; Zhao, B. Non-amide based zwitterionic poly (sulfobetaine methacrylate) s as kinetic hydrate inhibitors. Chem. Eng. Sci. 2021, 229, 116031. [CrossRef] 
45. Anklam, M.R.; York, J.D.; Helmerich, L.; Firoozabadi, A. Effects of antiagglomerants on the interactions between hydrate particles. Aiche J. 2008, 54, 565-574. [CrossRef]

46. Zerpa, L.E.; Salager, J.L.; Koh, C.A.; Sloan, E.D.; Sum, A.K. Surface chemistry and gas hydrates in flow assurance. Ind. Eng. Chem. Res. 2011, 50, 188-197. [CrossRef]

47. Nwankwo, H.U.; Akpan, E.D.; Olasunkanmi, L.O.; Verma, C.; Al-Mohaimeed, A.M.; Al Farraj, D.A.; Ebenso, E.E. $N$-substituted carbazoles as corrosion inhibitors in microbiologically influenced and acidic corrosion of mild steel: Gravimetric, electrochemical, surface and computational studies. J. Mol. Struct. 2021, 1223, 129328. [CrossRef]

48. Aldana-Gonzales, J.; Cervantes-Cuevas, H.; Alfaro-Romo, C.; Rodriguez-Clemente, E.; Uruchurtu-Chavarin, J.; Romero-Romo, M.; Montes de Oca-Yemha, M.G.; Morales-Gil, P.; Mendoza-Huizar, L.H.; Palomar-Pardave, M. Experimental and theoretical study on the corrosion inhibition of API 5L X52 steel in acid media by a new quinazoline derivative. J. Mol. Liq. 2020, 320, 114449. [CrossRef]

49. Haque, J.; Jafar Mazumder, M.A.; Quraishi, M.A.; Ali, A.S.; Aljeaban, N.A. Pyrrolidine-based quaternary ammonium salts containing propargyl and hydrophobic C-12 and C-16 alkyl chains as corrosion inhibitors in aqueous acidic media. J. Mol. Liq. 2020, 320, 114473. [CrossRef]

50. Hassan, H.H.; Abdelghani, E.; Amin, M.A. Inhibition of mild steel corrosion in hydrochloric acid solution by triazole derivatives: Part I. Polarization and EIS studies. Electrochim. Acta 2007, 52, 6359-6366. [CrossRef]

51. Al-Sabagh, A.M.; Nasser, N.M.; Farag, A.A.; Migahed, M.A.; Eissa, A.M.F.; Mahmoud, T. Structure effect of some amine derivatives on corrosion inhibition efficiency for carbon steel in acidic media using electrochemical and quantum theory methods. Egypt. J. Pet. 2013, 22, 101-116. [CrossRef]

52. Martínez, D.; Gonzalez, R.; Montemayor, K.; Juarez-Hernandez, A.; Fajardo, G.; Hernandez-Rodriguez, M.A.L. Amine type inhibitor effect on corrosion-erosion wear in oil gas pipes. Wear 2009, 267, 255-258. [CrossRef]

53. Aman, Z.M.; Pfeiffer, K.; Vogt, S.J.; Johns, M.L.; May, E.F. Corrosion inhibitor interaction at hydrate-oil interfaces from differential scanning calorimetry measurements. Colloids Surf. A Phys. Eng. Asp. 2014, 448, 81-87. [CrossRef]

54. Kelland, M.A. Production Chemicals for the Oil and Gas Industry, 2nd ed.; CRC Press: Boca Raton, FL, USA, 2014.

55. Mansfeld, F.; Tsai, S. Laboratory studies of atmospheric corrosion-I. Weight loss and electrochemical measurements. Corros. Sci. 1980, 20, 853-872. [CrossRef]

56. Xu, S.; Fan, S.; Fang, S.; Lang, X.; Wang, Y.; Chen, J. Pectin as an extraordinary natural kinetic hydrate inhibitor. Sci. Rep. 2016, 6, 1-7. [CrossRef] [PubMed]

57. Cui, G.; Guo, J.; Zhang, Y.; Zhao, Q.; Fu, S.; Han, T.; Zhang, S.; Wu, Y. Chitosan oligosaccharide derivatives as green corrosion inhibitors for P110 steel in a carbon-dioxidesaturated chloride solution. Carbohydr. Polym. 2019, 203, 386-395. [CrossRef] [PubMed]

Sample Availability: Samples of the compounds are available from the authors.

Publisher's Note: MDPI stays neutral with regard to jurisdictional claims in published maps and institutional affiliations.

(C) 2020 by the authors. Licensee MDPI, Basel, Switzerland. This article is an open access article distributed under the terms and conditions of the Creative Commons Attribution (CC BY) license (http://creativecommons.org/licenses/by/4.0/). 